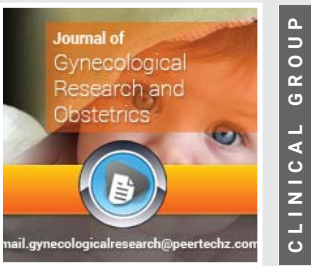

\title{
Average pubertal timing, characteristics and menstrual patterns of Nigerian girls: Implication for sex education
}

Received: 22 April, 2020

Accepted: 02 May, 2020

Published: 05 May, 2020

*Corresponding author: Faith C Diorgu, PhD, RM, Nurse/Midwife lecturer, Department of Nursing Science, University of Port Harcourt, Nigeria, Tel: +2348033401555: E-mail: faith.diorgu@uniport.edu.ng Keywords: Puberty; Menarche; Menstrual pattern https://www.peertechz.com

\section{Check for updates}

\author{
Faith C Diorgu ${ }^{1 *}$ and Kelechim N Diorgu ${ }^{2}$ \\ ${ }^{1}$ Department of Nursing Science, University of Port Harcourt, Nigeria \\ ${ }^{2}$ Oncology clinical research associate, Sarah Cannon research institute, Nashville, TN 37203, USA
}

\begin{abstract}
Introduction: Age at menarche reflects the beginning of sexual maturation and is affected by nutritional status and prevailing environmental conditions. This study examined the age at menarche, breast and pubic hair development of girls in Southern Nigeria and explored their menstrual pattern
\end{abstract}

Method: A cross-sectional descriptive study design was adopted, with structured questionnaire. Descriptive statistics was used to analyze data collected from 648 randomly selected girls in high school. Analysis was supported with SPSS software package.

Results: The average age of menarche was reported as $12.8 \pm 1.6$ years (ranging from 9 to 19 ). Twenty seven percent (27\%) of the girls had their menarche before age 12 and $61 \%$ had their menarche between 12 and 14 years, while (12\%) had menarche at age 15 to 16 years. The lowest age at menarche was 9 years with the highest being 16 years. The modal menarcheal age was 13 . At age 10 to 12 years only (16\%) respectively had developed breast and pubic hair. Majority of the respondents with breast (55\%) and pubic hair (55\%) were between ages 13 and 15 years.

Conclusion: The age at menarche and other menstrual patterns observed in this study are similar to adolescent pubertal timing and menstrual characteristics described by studies.

\section{Introduction}

Puberty is the time in life when a young person's body become sexually mature. This involves many changes in the body. For girls, puberty usually starts around age 11. But it can start as early as age 6 or 7. For boys, puberty begins around age 12. It can start as early as age 9. Puberty is a process. It occurs for several years. Most girls finish puberty by age 14. Most boys finish puberty at age 15 or 16 . The onset of puberty varies among individuals and can occur at different time for different persons. Not all children follow the same pattern of sexual development. Some girls develop breasts at a very young age but have no other signs of sexual development. Some children have pubic and armpit hair long before they show other signs of sexual growth. These changes in pattern are common. Earlier onset of puberty is occurring globally. Studies suggest earlier onset of breast and pubic hair development in girls than had previously been documented and there has been a gradual drop in age at menarche reported in most developed countries [1]. In Europe between the early 1800s and the mid-1900s, the average age at menarche decreased from 15-17 years to about 13- 13.5 years [1]. Another study found that the mean onset of breast development was 11.15 years, quite similar to what earlier US studies had found, but the mean age of menarche was 13.47 years, more than 0.5 years greater than in US studies

In the US, the mean age of menarche decreased from about 14.75 years in 1877 to about 13 years in 1950-1970 [2]. Other studies in the mid-1900s noted that the average age of onset of breast development was 10.6-11 years, and the average age of menarche, at least in white girls, was about 12.8 years. In low-and middle-income countries, which have experienced socio-economic developments and improved sanitation more recently have witnessed a strong secular trend in the reduction 
of menarcheal age [3,4]. Studies have also shown a secular trend toward earlier development of breasts and pubic chair [5]. In the 1990s, two American studies turned our attention towards new secular pubertal trend in both girls and boys [6]. However, data from European populations study done in Europe at similar time failed to demonstrate the trends. Current studies now suggest similar radical changes in European population [6] and to a lesser extent in European boys. In addition, a similar increase in the number of girls discussed as having precocious puberty (PP) has been reported [7]. Lawson Wilkins Pediatric Endocrine Society (LWPES) was prompted to recommend a lowering of the age limit for evaluation of PP in girls [7]. The recommendations were based on the concerns of overlooking treatable pathological conditions underlying the precocious onset of puberty, and have led many experts to question the recommendations. Trends across many populations show that the shift in age at pubertal onset has been concurrent with increases in height, suggesting that improved nutrition and socioeconomic conditions have contributed to both trends [8]. In addition, studies within several populations have shown a converse association between height and age of pubertal onset. Furthermore, the secular trends in pubertal development have been accompanied by an increase in BMI in children and studies on the role of overweight and obesity in pubertal development have gathered much attention [3,5]. There is evidence of an association between higher BMI in childhood or adolescence and earlier onset of puberty in girls [5,9]. Menstruation has a variable pattern within a few years of puberty which may not be well understood by many adolescent girls. Providing accurate information on menstruation is necessary to reduce anxiety, menstrual morbidity and improve reproductive health of these populations. The aim of the study is to determine the average pubertal timing, characteristics and menstrual pattern of school girls in Nigeria to enable a focused sex education to the population.

\section{Material and methods}

The study is a cross-sectional descriptive study of average pubertal timing, characteristics and menstrual pattern of 648 adolescent girls in four selected Secondary Schools (High school) in Nigeria. The schools are two government and two private mixed secondary schools located in Port Harcourt city of Nigeria. The schools are regarded as among the top secondary schools in Port Harcourt city of Nigeria. They were purposively chosen because, female students dominates in these schools and the female students comprised of girls in their early, middle and late adolescents from different ethnic and socioeconomic family classes who are resident in Port Harcourt city and its suburbs. The girls were selected according to WHO definition of adolescence, which is between 10 to 19 years (WHO 2006)[10]. Pre-tested structured questionnaire was used for data collection. Questions asked included age at menarche, breast and pubic hair development. Menstrual patterns like: length of menstrual cycle, bleeding durations and presence of menstrual pains were also asked. The questionnaire was properly explained to students to facilitate correct response from students. The questionnaire was distributed and collected immediately on the spot to avoid peers influence on individual responses. Informed consent was obtained from the adolescent girls and the head of the school. Due approval was obtained from the institutional Ethic committee. Six hundred and ninety eight (698) questionnaire was distributed, 658 were filled correctly, of this, $10(1.4 \%)$ girls did not yet experience their first menstruation, thus were not included in the study. So, we had 648 as the total number of questionnaire from the 4 selected schools. This study therefore, is based on 648 questionnaire. The questionnaire had questions on age, date of birth, age at menarche, regularity of menstruation, length of cycle, duration of menses and pre- menstrual symptoms and dysmenorrhea. The data gathered were coded, entered and analyzed using Statistical Package for Social Science (SPSS) version 10.0 for window.

The age of the school girls in the study was between 10 - 19 years with mean of $160.93 \pm$ years. The average age of menarche was reported as $12.8 \pm 1.6$ years (ranging from 9 to 19). One hundred and seventy six (27\%) of the girls had their menarche before 12 years and 396 respondents $(61 \%)$ out of 648 girls had their menarche between 12 and 14 years, while 76 respondents $(29 \%)$ had menarche at age 15 to 16years.The result shows the lowest age at menarche was 9 years with the highest being 16 years. The modal menarcheal age was 13 . At age 10 to 12 years only 102 (16\%) and 100 (15\%) had developed breast and pubic hair respectively. Majority of the respondents with breast 356 (55\%) and pubic hair362 (56\%) development fall between age bracket 12 and 14 years. While the lowest hair $16 \%$ for breast and $15 \%$ for pubic development fall between ages 10 and 12. Table 1 . Shows the percentage distribution of the age at menarche and breast and pubic hair development.

Table 1: Percentage distribution of 10-year-old to 19-year-old girl children with age at menarche, breast and pubic hair development.

\begin{tabular}{|c|c|c|c|}
\hline $\begin{array}{c}\text { Chronological Age/ } \\
\text { Frequency }\end{array}$ & Age at Menarche & $\begin{array}{c}\text { Girls with Breast } \\
\text { Development }\end{array}$ & $\begin{array}{c}\text { Girls with pubic } \\
\text { hair development }\end{array}$ \\
\hline $10-12$ & $9-11$ Year & $\mathrm{N}=102$ & $\mathrm{~N}=100$ \\
$\mathrm{~N}=108$ & $\mathrm{~N}=176$ & $(16 \%)$ & $(15 \%)$ \\
$(16.7 \%)$ & $(27 \%)$ & $\mathrm{N}=356$ & $\mathrm{~N}=362$ \\
$13-15$ & $12-14$ Year & $(55 \%)$ & $(56 \%)$ \\
$\mathrm{N}=354$ & $\mathrm{~N}=396$ & $\mathrm{~N}=190$ & $\mathrm{~N}=186$ \\
$(54.6 \%)$ & $(61 \%)$ & $(29 \%)$ & $(29 \%)$ \\
\hline $16-19$ & $15-16$ Year & $\mathrm{N}=76$ & \\
\hline $\mathrm{N}=186$ & $(12 \%)$ & & \\
\hline$(28.7 \%)$ & & &
\end{tabular}

\section{Menstrual pattern}

Length of menstrual cycle. Among the 648 respondents, the average duration of the menstrual cycle was $29.8 \pm 3.3$ days. A large number of the girls $455(69 \%)$ had menstrual cycle duration of 28 to 35 days, which is considered as normal. While a very small number $162(25 \%)$ had cycle length $<28$ days and remaining 31 girls $(5 \%)$ had cycle length $>35$ days. Bleeding duration Majority of the girls 489 (75.4\%) reported bleeding duration as $4-5$ days which is normal, few of the girls $129,20 \%$ reported less than 4 days and $30,5 \%$ participants the duration was more than 5 days. Menstrual pain. Two hundred and twenty four of the girls, $35 \%$ had menstrual pain, while 
$424,65 \%$ do not have menstrual pain which is very significant. Table 2 Shows the Percentage distribution of length of cycle, bleeding duration and menstrual pains of the respondents.

Table 2: Percentage distribution of 10-year-old to 19-year-old girls menstrual pattern.

\begin{tabular}{|c|c|c|c|}
\hline $\begin{array}{c}\text { Sub - group } \\
\text { by age }\end{array}$ & $\begin{array}{c}\text { Length of menstrual cycle } \\
\text { days }\end{array}$ & $\begin{array}{c}\text { Bleeding duration by } \\
\text { days }\end{array}$ & Menstrual pain \\
\hline $10-12$ & $28-35$ days $67(62 \%)$ & $4-5$ days $54(50 \%)$ & Yes- $68(63 \%)$ \\
$\mathrm{N}=108$ & $<28$ days $39(36 \%)$ & $<4$ days $48(44 \%)$ & No- $40(37 \%)$ \\
$(16 \%)$ & $>35$ days $2(2 \%)$ & $>5$ days $6(6 \%)$ & \\
\hline & $28-35$ days & & \\
$13-15$ & $236(66.6 \%)$ & $4-5$ days $283(80 \%)$ & Yes $-118(33 \%)$ \\
$\mathrm{N}=354$ & $<28$ days $97(27.4 \%)$ & $<4$ days $53(15 \%)$ & No- $236(67 \%)$ \\
$(55 \%)$ & $>35$ days & $>5$ days $18(5 \%)$ & \\
\hline $16-17$ & $28-35$ days $152(81 \%)$ & $4-5$ days $152(82 \%)$ & Yes $-38(20 \%)$ \\
$N=186$ & $<28$ days $26(14 \%)$ & $<4$ days $28(15 \%)$ & No- $148(80 \%)$ \\
$(29 \%)$ & $>35$ days $8(5 \%)$ & $>5$ days $6(3 \%)$ & \\
\hline
\end{tabular}

\section{Discussion}

Pubertal timing is the level of development contributed by both genetic and environmental factors to the start of pubertal maturation relatively within a group. There is a great deal of variation in the timing of pubertal maturation across adolescents. A significant body of knowledge shows that variations in pubertal timing have psychological, social, and health consequences [11,12]. In particular, research consistently demonstrates that early timing is associated with negative consequences among adolescent girls. Furthermore, mean ages at menarche vary considerably between girls across different countries or across different ethnic groups [13]. Reasons behind this international variation remain poorly understood, could be because few comparative analyses have been conducted on such a large scale, the variables affecting the timing of these events within populations do not necessarily explain differences between populations. In order to characterize patterns in the variation of ages at menarche across populations, it is essential to investigate issues on large spatial and/or temporal scales in order to place the findings within a broader perspective.

The result shows that pubertal timing and menstrual characteristics are individualized. The age at menarche of respondents does not seem to define the menstrual characteristics such as type of menstrual cycle, bleeding duration and presence or absence of menstrual pain. Average length of menstrual cycle was reported to be normal in majority $455(69 \%)$ of the girls (28-35 days). Normal length of the cycle is considered as 21-35 days [14]. This is in view of the fact that the cycles are already regularized by this age. No association between length of cycle and menstrual pain was noted. However, different studies have suggested that menstrual pain is more prevalent in women with longer cycles [15].

On the other hand, menstrual bleeding duration of 5 days and over was an important risk factor for menstrual pain. Bleeding duration was found to be significantly normal in majority of the girls. Girls who had bleeding duration more than 5 days had more chance of getting menstrual pain. This finding is compatible with the result showing that the risk of menstrual pain is higher in women with long menstrual flows [16]. As an explanation for this, some of the researchers have reported that daughters of mothers who have menstrual complaints also experienced menstrual discomfort, which is related to behavior that is learned from the mother (Patel et al 2006). Women of reproductive age experience symptoms during late luteal phase of their menstrual cycle typically present as discomfort.

With regards to breast and pubic hair development, clinicians have long assumed that onset of breast development or pubic hair prior to age 8 years signals a good chance of endocrine pathology and requires an extensive evaluation. In view of the evidence presented earlier, it now appears that the great majority of early-maturing girls (using the 8-year definition) are normal girls who are at the early end of the normal age distribution for pubertal onset. Furthermore, it is now recognized that early breast development can progress very slowly or not at all [17] underlining the need for a period of observation before undertaking any clinical decision to suppress the hypothalamic-pituitary-gonadal axis. Given the great variability around puberty in girls with signs of early maturation, it is suggested that in making decisions on testing and treatment, much attention should be paid to the rate of progression of pubertal findings as to their age of appearance. Generally, child growth and development is biologically supported. Both leptin and estrogen, hormones produced in adipose cells, are thought to play a role in the stimulation of pubertal development [18]. Overweight girls have been found to have higher concentrations of estrogen, potentially expediting the pubertal process $[19,20]$. For a girl, the timing of maturation of the adrenal gland and increase in adrenal androgens that occurs in early childhood may contribute to both the timing of the mid childhood growth spurt and other maturational events, such as puberty [18]. Such a connection would suggest that a larger body size at earlier years of age is a marker for a child's overall developmental trajectory. To my knowledge the study may be the first study to capture age at pubertal timing and menstrual characteristics patterns of girls in this part of Nigeria. It is of utmost relevant as many of the girls are getting into maturity at an earlier age. Thus it call for intentional sex education as the children would be taking the appearance of young adult.

There are certain limitations of the study firstly, it has been conducted in selected colleges in single district, and therefore the sample may not be representative of all colleges in Port Harcourt, Nigeria. And since the nature of data was self-reporting, it may have resulted in under-reporting of the conditions in few cases.

\section{Conclusion}

In light of the above trends, the view that onset of any pubertal changes prior to age 8 years requires an extensive evaluation should be reevaluated. The majority of such early maturing girls are normal girls at the early end of the age distribution for pubertal onset. As much attention should be paid to the rate of progression of pubertal findings as to their age of appearance. The present results demonstrate that on a 
large spatial scale different factors may be responsible for the observed variation in age at menarche, whereas a single factor may explain the menstrual patterns. In fact, age at menarche seems to be closely related to extrinsic factors such as living conditions and, especially, the energy balance allocated to individuals.

\section{Acknowledgement}

The authors gratefully acknowledged Dr C. TobI-West, and Dr EO Oranu for their contributions. We also acknowledge all the high school students who participated.

\section{Authors contributions}

FCD had primary responsibility for protocol development, data collection, analysis and writing of the paper. KND performed final data analysis, participated in the development of the protocol and analytical framework for the study and contributed to the writing of the study.

\section{References}

1. Henrichs KL, McCauley HL, Miller E, Styne DM, Saito N, et al. (2014) Early menarche and childhood adversities in a nationally representative sample. Int J Pediatr Endocrinol 14. Link: https://bit.ly/2z6vJdW

2. García Cuartero B, Gónzalez Vergaz A, Frías García E, Arana Cañete C, Díaz Martínez E, et al. (2010) Assessment of the secular trend in puberty in boys and girls. An Pediatr (Barc) 73: 320-326. Link: https://bit.ly/2YpHfMn

3. James-Todd T, Tehranifar P, Rich-Edwards J, Titievsky L, Terry MB (2010) The impact of socioeconomic status across early life on age at menarche among a racially diverse population of girls. Ann Epidemiol 20: 836-842. Link: https://bit.ly/2YqdRFO

4. Opare-Addo PM, Stowe M, Ankobea-Kokroe F, Zheng T (2012) Menarcheal and pubertal development and determining factors among schoolgirls in Kumasi, Ghana. J Obstet Gynaecol 32: 159-165. Link: https://bit.ly/2zJaYW6

5. Biro FM, Greenspan LC, Galvez MP, Pinney SM, Teitelbaum S, et al. (2013) Onset of breast development in a longitudinal cohort. Pediatrics 132: 10191027. Link: https://bit.ly/2VTwK2e

6. Rigon F, Bianchin L, Bernasconi S, Bona G, Bozzola M, et al. (2010) Update on age at menarche in Italy: toward the leveling off of the secular trend. J Adolesc Health 46: 238-244. Link: https://bit.ly/3fbkZf8

7. Perry JR, Murray A, Day FR, Ong KK (2015) Molecular insights into the aetiology of female reproductive ageing. Nat Rev Endocrinol11: 725-734. Link: https://bit.ly/3d6tc29

8. Islam MS, Hussain MA, Islam S, Mahumud RA, Biswas T, et al. (2017) Age at menarche and its socioeconomic determinants among female students in an urban area in Bangladesh. Sex Reprod Healthc 12: 88-92. Link: https://bit.ly/2SuOSxb

9. Lee JM, Appugliese D, Kaciroti N, Corwyn RF, Bradley RH, et al. (2007) Weight status in young girls and the onset of puberty. Pediatrics 119: e624. Link: https://bit.ly/3fdWlu7

10. WHO Multicentre Growth Reference Study Group (2006) WHO child growth standards based on length/height, weight and age. Acta Paediatr Suppl 450 76-85. Link: https://bit.ly/2yakDVy
11. Bleil ME, Adler NE, Appelhans BM, Gregorich SE, Sternfeld B, et al. (2013) Childhood adversity and pubertal timing: Understanding the origins of adulthood cardiovascular risk. Biol Psychol 93: 213-219. Link: https://bit.ly/2z54laN

12. Canoy D, Beral V, Balkwill A, Wright FL, Kroll ME, et al. (2015) MillionWomen Study Collaborators. Age at menarche and risks of coronary heart and other vascular diseases in a large UK cohort. Circulation 131: 237-244. Link: https://bit.ly/3dbBaHE

13. Al-Sahab B, Ardern Cl, Hamadeh MJ, Tamim H (2010). Age at menarche in Canada: Results from the National Longitudinal Survey of Children \& Youth. BMC Public Health 10: 736. Link: https://bit.ly/3bWTowb

14. Munster K, Schmidt L, Helm P (1992) Length and variation in the menstrual cycle--- a cross-sectional study from a Danish county. Br J Obstet Gynaecol 99: 422-429. Link: https://bit.ly/2KOQyxr

15. El-Gilany AH, Badwai J, El-Fedway S (2005) Epidemiology of dysmenorrhea among adolescent students in Mansoura, Egypt. East Mediterr Health $\mathrm{J} 11$ 155-163. Link: https://bit.ly/2YrKymk

16. Unsal A, Ayranci U, Tozun M, Arslan G, Calik E (2010) Prevalence of dysmenorrhea and its effect on quality of life among a group of female university students. Ups J Med Sci 115: 138-145. Link: https://bit.ly/3fa1hjP

17. Palmert MR, Malin HV, Boepple PA.(1999) Unsustained or slowly progressive puberty in young girls: initial presentation and long-term followup of 20 untreated patients. J Clin Endocrinol Metab 84: 415-423. Link: https://bit.ly/3dcxpRV

18. Gardner DG, Shoback D (2011) Greenspan_s basic \& clinical endocrinology New York: McGraw Hill Lange. Link: https://bit.ly/3aPOWha

19. Demerath EW, Li J, Sun SS, Chumlea WC, Remsberg KE, et al. (2004) Fiftyyear trends in serial body mass index during adolescence in girls: the Fels Longitudinal Study. Am J Clin Nutr 80: 441-446. Link: https://bit.ly/3b095Bo

20. Patel V, Tanksale V, Sahasrabhojanee M, Gupte S, Nevrekar P (2006) The burden and determinants of dysmenorrhea: A population-based survey of 2262 women in Goa, India. BJOG 113: 453-463. Link: https://bit.ly/35meL7J

\section{Discover a bigger Impact and Visibility of your article publication with}

\section{Peertechz Publications}

\section{Highlights}

* Signatory publisher of ORCID

* Signatory Publisher of DORA (San Francisco Declaration on Research Assessment)

* Articles archived in worlds' renowned service providers such as Portico, CNKI, AGRIS, TDNet, Base (Bielefeld University Library), CrossRef, Scilit, J-Gate etc.

- Journals indexed in ICMJE, SHERPA/ROMEO, Google Scholar etc.

* OAI-PMH (Open Archives Initiative Protocol for Metadata Harvesting)

* Dedicated Editorial Board for every journal

* Accurate and rapid peer-review process

* Increased citations of published articles through promotions

* Reduced timeline for article publication

Submit your articles and experience a new surge in publication services (https://www.peertechz.com/submission).

Copyright: @ 2020 Diorgu FC, et al. This is an open-access article distributed under the terms of the Creative Commons Attribution License, which permits unrestricted use, distribution, and reproduction in any medium, provided the original author and source are credited.

Citation: Diorgu FC, Diorgu KN (2020) Average pubertal timing, characteristics and menstrual patterns of Nigerian girls: Implication for sex education . J Gynecol Res Obstet 6(1): 010-013. DOI: https://dx.doi.org/10.17352/jgro.000078 